\title{
\#Rolezinhos: Análise de redes sociais e construção de sentidos no discurso de tuiteiros acerca do \#Protestodos Pintas em Natal (RN)
}

\author{
Maria das Graças Pinto Coelho \\ Daniel Dantas Lemos
}

Resumo: Este artigo apresenta resultados alcançados por pesquisa desenvolvida a partir da análise das manifestações no Twitter acerca do \#ProtestodosPintas, ocorrido em Natal (RN) em 21 dezembro de 2013. A pesquisa constatou que os sentidos construídos nas redes sociais da Internet acerca do \#ProtestodosPintas foram negativos, com a rede se articulando em torno dos perfis @ tribunadonorte e @BlogdoBG. As interações nas redes sociais analisadas acerca do \#ProtestodosPintas se deram estimulando um imaginário social sem identidade política em que o desejo de reconhecimento dos jovens das classes populares foi classificado como expressão de violência e de barbárie. Os 340 tweets coletados foram analisados a partir das ferramentas propostas pelas teorias de análise de redes sociais assim como os enunciados, que foram analisados a partir dos pressupostos da análise do discurso.

Palavras-Chave: sociabilidade; análise de redes sociais; análise do discurso.

Abstract: \#Rolezinhos: Social network analysis and meaning construction in twitter users' discourses upon \#ProtestodosPintas in Natal (RN) - This paper conveys the outputs of a research developed from the analysis of Twitter's utterances about \#ProtestodosPintas, that took place in the city of Natal (RN) in December 21st, 2013. We found out that the meanings constructed in the digital social networks about \#ProtestodosPintas were negative, since the network has hung around two profiles, namely @tribunadonorte and @BlogdoBG. The social network interactions under analysis occurred by stimulating a retrograde social imaginary, 
when the youngsters' desires for acknowledgment were typified as an expression of violence and barbarity. The 340 tweets here collected were analyzed according to the tools proposed by social network analytical theories, as well as the utterances, based on the discourse analysis presuppositions.

Palavras-Chave: sociability; social network analysis; discourse analysis.

\section{Notas introdutórias}

O \#ProtestodosPintas ${ }^{1}$, um protesto ou o grito dos quase excluídos, foi um flash mob da periferia de Natal (RN) realizado em 21 de dezembro de 2013. No caso natalense, o protesto deixou de ser um movimento difuso de diversão e política para se transformar em um fenômeno de divisão social, estranhamento e preconceito radical contra a reinvenção das sociabilidades, contra um jovem que emerge de um lugar distante do centro, onde habitam jovens da classe média verdadeira, contra tudo que não represente os valores inseridos na linha do apartheid social brasileiro. Uma demarcação aleatória que privilegia gostos e valores da classe média tradicional. Uma linha invisível que não reconhece os novos espaços de sociabilidades criados pelos jovens de baixa renda.

As redes sociais digitais são transformadas em campo de batalha entre os que apóiam os desclassificados sociais e os que preferem reformar velhas opiniões sobre hábitos de classe e consumo juvenis. No limiar do estranhamento, os jovens adeptos dos encontros grupais são denominados de "bárbaros", porque provocam "arrastões" em shoppings, pelo time que cria constructos sobre as práticas, gostos e apegos simbólicos dos desclassificados.

Aqui nos ocorre evocar Miller (1997) que, apropriadamente, discorre sobre a repulsa e o nojo (disgust), atração e medo da proximidade de tudo aquilo que consideremos diferentes. Embora Miller (1997) centre seus fundamentos na emoção e no sentimento de nojo e repulsa que afeta todo o sistema nervoso do ser humano quando se depara com algo que está fora da ordem, também associa essa emoção à classificação social e ao controle dos sujeitos nas interações socialmente mediadas. Como afirma ele, e é o que nos interessa aqui para explicitar o constructo que provoca o estranhamento de jovens em redes, as "sociedades 'civilizadas' despertaram as sensibilidades ao nojo para transformálo em um componente chave do controle social e da ordem psíquica" (MILLER, 1997, p. 5). Tal constatação parece dar conta de explicar esse fenômeno que permite a expressão pública de estranhamento e preconceito em redes digitais.

Também não podemos esquecer que o fluxo interacional em rede é protagonizado por atores sociais, agora representados por identidades cada vez mais complexas, e por novos modos de interação que surgem na ambiência digital. A interação entre

1 São conhecidos como "pintas" em Natal os jovens negros de periferia, normalmente reconhecidos por um ethos que inclui uma vestimenta característica, gosto musical, adereços e modo de andar e dançar, correspondendo ao que, em outras cidades brasileiras, como maloqueiros (em São Paulo), ou pirangueiros (em Fortaleza), entre outros. O termo surgiu na cena natalense como caracterização do jovem descolado nos anos de 1970. 
esses atores, protagonistas e seguidores, que presupõe a presença dos objetos digitais nas relações sociais, também remarca o lugar da autoridade, a voz que coloca rumo, empresta significados, aos acontecimentos que são relatados nas redes sociodigitais. São os hubs de rede que se investem na autoridade que produz e reproduz a interpretação dos acontecimentos sociais.

Concomitante à exteriorização dos sentidos resultante da ação social dos 'pintas' observamos as autoridades, sites de grandes jornais e blogueiros realizarem a própria analítica dos acontecimentos para imprimirem controle e se confundirem com os processos de mediação das chamadas "mídias tradicionais". Em princípio, descartaram a autonomia tecno-discursiva por parte dos atores sociais que protagonizam os acontecimentos. E no lugar de chamar atenção para marcas de um processo interpretativo, de natureza heterorreferente, cujo objeto seria os fatos externos (FAUSTO NETO, 2008), desenvolveram trabalho de leitura e discursividade sobre os acontecimentos protagonizados pelos jovens "pintas", de forma a produzir estranhamento sobre um grupo que interage e recria sociabilidades, sem permitir aos jovens a afirmação de suas identidades periféricas.

Na sequência, a análise deste trabalho se desenvolve a partir de dados quantitativos coletados no Twitter, utilizando-se de categorias analíticas para situar o protagonismo das autoridades discursivas na rede. O corpus desta pesquisa coletou 340 tweets publicados entre os dias 14 e 31 de dezembro de 2013. A coleta foi realizada no dia 31 de janeiro de 2014 utilizando como ferramenta de busca e filtragem aquela disponibilizada no site da rede social, a partir dos seguintes parâmetros: \#ProtestodosPinta, Protesto dos Pinta, \#ProtestodosPintas, Protesto dos Pintas, \#midwaymall, Midway.

O Protesto dos Pintas foi marcado para o sábado, 21 de dezembro de 2013, no Midway Mall. Tal manifestação foi motivada pelos relatos de diversos sujeitos em redes sociais de que no sábado anterior, dia 14 de dezembro de 2013, os seguranças do referido shopping center impediram o acesso às dependências do estabelecimento de jovens negros e vestidos de acordo com o estereótipo dos chamados "pintas". É em virtude dessa cronologia nossa opção por recortarmos como corpus as publicações no Twitter entre os dias 14, quando ocorreu o episódio desencadeador, e o dia 31, a fim de podermos abranger a totalidade das manifestações a respeito dos eventos dos dias 14 e 21 .

\section{Análise de redes}

Neste trabalho, nos propusemos a realizar uma análise de redes alinhada a ferramentas da análise do discurso. Para isso, em primeiro lugar, nos utilizamos do Gephi (2014), software livre que nos possibilitou, a partir dos acessos ao corpus selecionado para a pesquisa, a geração de grafos analíticos da rede em destaque.

Os tweets selecionados foram classificados a partir da formação discursiva manifesta a favor ou em oposição ao \#ProtestodosPintas - mesmo aqueles que não manifestavam 
juízo de valor acerca do evento, em tom de virtual neutralidade, contribuíram para a construção de uma possível imagem positiva do evento.

Dos 340 tweets publicados no período de coleta, 143 deles foram favoráveis ou não emitiram juízo acerca do Protesto dos Pintas realizado no dia 21 de dezembro de 2013 no Midway Mall, em Natal. Portanto, outras 197 publicações na rede social naquele período, que rechaçavam a manifestação, foram classificadas como contrárias ao protesto, por se filiarem a uma posição discursiva crítica ao evento. Foram 181 perfis do Twitter que fizeram publicações sobre o assunto.

A rede analisada, portanto, possui 181 nós. E tais nós constituíram 84 arestas ou seja, os 181 sujeitos que se manifestaram no período acerca do Protesto dos Pintas constituíram apenas 84 interações diferentes. Foram, por sua vez, 83 os sujeitos que publicaram tweets sobre o tema sem estabelecer qualquer tipo de interação com outros nós da rede. Literalmente, falaram sozinhos. Desta maneira, as 84 interações na rede que se estabeleceu em torno do Protesto dos Pintas foram realizadas por 98 usuários.

Preocupa-nos, neste trabalho, analisar o papel social de um ou mais indivíduos em uma determinada rede social - em nosso caso, na análise de publicações no Twitter acerca do Protesto dos Pintas, realizado em Natal, no dia 21 de dezembro de 2013. Desse modo, na classificação que Recuero (2005, p. 3) sistematiza, aproximamo-nos da análise de uma rede personalizada (ego-centered network). A autora, a partir do que afirmam Garton et al. (1997, online, apud RECUERO, 2005, p. 3), explica que a análise de redes sociais procura ir além dos atributos individuais, pensando as relações entre os atores sociais e que, por isso, concentra-se em

novas 'unidades de análise', tais como: relações (caracterizadas por conteúdo, direção e força), laços sociais (que conectam pares de atores através de um ou mais relações), multiplicidade (quanto mais relações um laço social possui, maior a sua multiplicidade) e composição do laço social (derivada dos atributos individuais dos atores envolvidos) (RECUERO, 2005, p. 3).

No uso dos grafos, dos quais falaremos a seguir, os laços sociais se convertem arestas e, os atores, em nós da rede. Em nossa pesquisa, utilizaremos, dentre as unidades de análise mencionadas por Recuero (2005), as relações e a composição do laço social - este último, especialmente, quando descrevermos e analisarmos os hubs presentes na rede analisada.

Na tarefa de análise de redes sociais, iremos lançar mão da teoria dos grafos. Segundo Melo et al (2014, p. 1), a "utilização de grafos é essencial nesta aplicação pois se demonstra de maneira bem mais simples e interativa, o comportamento de uma aglomeração de objetos". Desse modo, complementam os autores, podem ser deduzidos e analisados "vários aspectos de uma rede, tais como grau, centralidade, proximidade, intermediação e comunidade" (MELO et al, 2014, p. 1). 
É do trabalho de Melo et al (2014), por sua objetividade, que retiraremos as definições acerca dos termos mais utilizados na análise de redes a partir dos grafos. Um grafo é uma representação visual do tipo de interação que se estabelece entre dois pontos de uma determinada rede. No caso de redes sociais, os pontos que constituem um grafo são sujeitos que interagem e se relacionam. Assim, dizem Melo et al (2014, p. 1), "um grafo é um conjunto de pontos ligados por um conjunto de arcos ou arestas".

Já a noção de grau se refere à quantidade de arestas ligadas a cada um dos nós ou seja, quanto mais arestas se liguem a um nó mais alto será seu grau. A partir disso, um dos conceitos principais para o nosso trabalho é a definição de hubs. Hubs têm elevado grau, ou seja, como o dizem Melo et al (2014, p. 2), "são nós com alta taxa de ligações". Quando as arestas são dirigidas ao hub, ele é chamado de autoridade na rede. Caso suas interações partam a partir dele, são conhecidos como distribuidores de informação. Em nossa pesquisa, conforme o grafo a seguir, dois nós se comportaram como hubs na forma de autoridade na rede. O perfil @ tribunadonorte, do jornal diário Tribuna do Norte, tem 23 arestas, nenhuma delas direcionada a partir do perfil, tendo o maior grau de autoridade da rede. Em seguida destaca-se o perfil @BlogdoBG, do Blog do BG, com 19 interações diferentes, manifestadas em arestas, sendo apenas uma direcionada a partir de si.

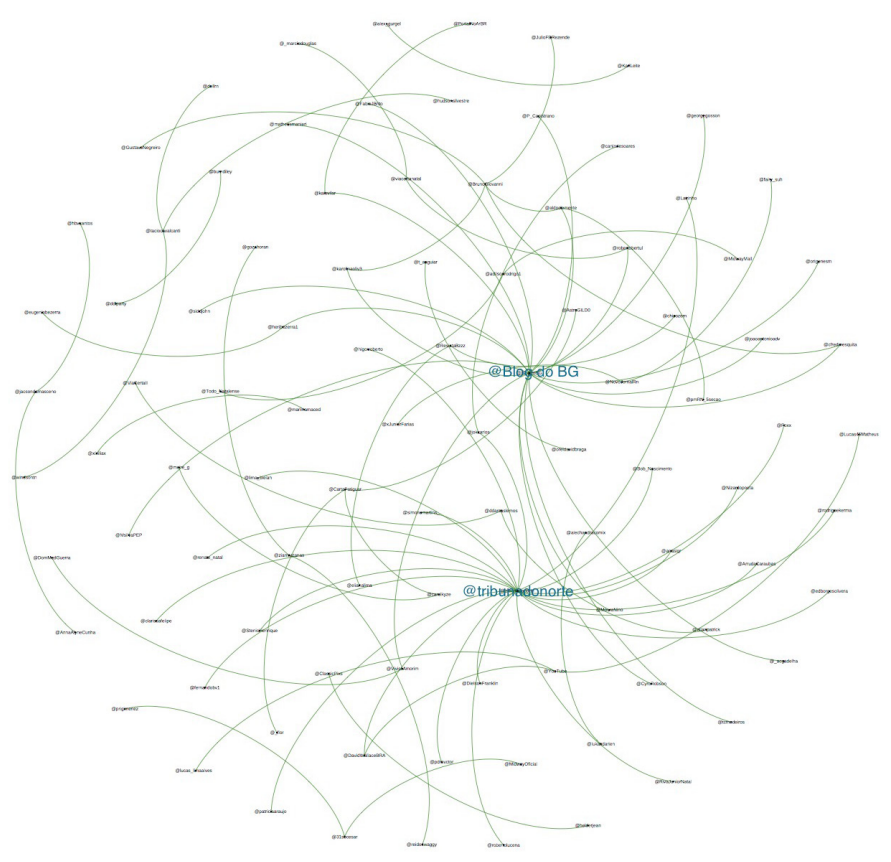

Fig. 1. Grafo das manifestações sobre Protesto dos Pintas. 
Também nos aproximamos em nossa análise do modelo de redes "sem escalas", conforme apresentada por Barabási (2003 apud RECUERO, 2005, p. 8), a partir da ideia de que "quanto mais conexões um nó possui, maiores as chances de ele ter mais novas conexões", como o diz Recuero (2005, p. 8). Nesse formato, a rede não é igualitária uma vez que os dois hubs concentram a maior parte das conexões - ambos têm 42 das 84 arestas de todo sistema, ou seja, 50\% de todas as interações se concentram em apenas dois nós. Por suas características, os perfis @tribunadonorte e @BlogdoBG são "ricos" que tendem a receber sempre mais conexões - inclusive por se tratarem de perfis relacionados a veículos de comunicação, possibilitando aos usuários da rede que recebam mais informações, além de, principalmente no caso em análise, estimularem a possibilidade de uma maior repercussão e abrangência dos tweets direcionados aos dois perfis.

Outra noção apresentada por Melo et al (2014, p. 3) e que podemos utilizar aqui é o conceito de integração, que consiste na variedade de ligações de nós entre si em uma rede possibilitando que a informação flua mais fácil por ela. O grau de integração da rede formada em torno do Protesto dos Pintas será importante na construção de significação do evento junto à opinião pública, uma vez que, além de os dois nós citados (@tribunadonorte e @ BlogdoBG) terem elevado grau de autoridade na rede, as manifestações contrárias ao evento eram maioria e estavam relativamente bem integradas.

O perfil @tribunadonorte publicou cinco tweets sobre o tema no período analisado, sendo que dois deles foram favoráveis aos protestos (denominados positivos na tabela abaixo), enquanto os demais manifestaram uma posição discursiva de oposição (negativos), a partir do uso de termos como "confusão", "policiamento (...) reforçado":

\begin{tabular}{|c|c|c|}
\hline Tweet & Data & Valor \\
\hline $\begin{array}{r}\text { 'Protesto dos Pinta' acaba em confusão no Midway http:// } \\
\text { tribuna.me/n87mu }\end{array}$ & 21 de dezembro de 2013 & Negativo \\
\hline $\begin{array}{c}\text { Policiamento ao redor do Midway será reforçado para } \\
\text { 'Protesto dos Pinta' http://tribuna.me/n87k1 }\end{array}$ & 21 de dezembro de 2013 & Negativo \\
\hline $\begin{array}{r}\text { Confira fotos do protesto no Midway Mall http://tribuna. } \\
\text { me/a4nl }\end{array}$ & 22 de dezembro de 2013 & Positivo \\
\hline $\begin{array}{r}\text { Sete do 'Protesto dos Pintas' são detidos e depois } \\
\text { liberados http://tribuna.me/n87n7 }\end{array}$ & 22 de dezembro de 2013 & Negativo \\
\hline Imagens do 'Protesto dos Pintas' http://tribuna.me/v456 & 23 de dezembro de 2013 & Positivo \\
\hline
\end{tabular}

Tab. 1. Tweets publicados pelo perfil @tribunadonorte.

Apesar de uma quantidade relativamente pequena de tweets sobre o tema do Protesto dos Pintas no período, o perfil @tribunadonorte teve 23 interações dirigidas a si por outros usuários do Twitter - o perfil não respondeu a nenhum nem citou nenhum usuário em suas postagens. Das 23 interações, 19 se ligaram a uma posição discursiva contrária 
ao protesto e 4 tiveram um posicionamento favorável ao evento. Enquanto $40 \%$ dos tweets da @tribunadonorte manifestavam um discurso favorável ao protesto (qualificados como positivos na tabela abaixo), apenas $17,4 \%$ de suas interações foram assim classificados - o que reforça a percepção de que o sentido construído para o Protesto dos Pintas junto aos usuários do twitter tenha sido de rejeição com a influência dos hubs destacados na rede analisada:

\begin{tabular}{|c|c|c|}
\hline Perfil & Interação & Qualificação \\
\hline @ArrudaCaraubas & $\begin{array}{l}\text { (RT) @tribunadonorte: Policiamento ao redor do Midway será } \\
\text { reforçado para 'Protesto dos Pinta' http://flip.it/ct0xW }\end{array}$ & Negativo \\
\hline @anasiqr & $\begin{array}{c}\text { Protesto virou moda, até 'os pinta'. Já pensou // “@ } \\
\text { tribunadonorte: 'Protesto dos Pinta' acaba em confusão no } \\
\text { Midway http://tribuna.me/n87mu " }\end{array}$ & Negativo \\
\hline @Bob_Nascimento & $\begin{array}{l}\text { (RT) 'Protesto dos Pinta' acaba em confusão no Midway http:// } \\
\text { tribuna.me/tw/n87mu via @tribunadonorte }\end{array}$ & Negativo \\
\hline @canindesoares & $\begin{array}{c}\text { (RT) "Protesto dos Pinta" acontece dia } 28 \text { no shopping } \\
\text { Midway > http://tribuna.me/tw/n875j via @ tribunadonorte }\end{array}$ & Positivo \\
\hline$@$ clarissafelipe & $\begin{array}{l}\text { "@tribunadonorte: Policiamento ao redor do Midway será } \\
\text { reforçado para 'Protesto dos Pinta' http://tribuna.me/n87k1 " } \\
\text { Isso é Natal. }\end{array}$ & Positivo \\
\hline @DavidWallaceBRA & $\begin{array}{l}\text { (RT) 'Protesto dos Pinta' acaba em confusão no Midway http:// } \\
\text { tribuna.me/tw/n87mu via @tribunadonorte }\end{array}$ & Negativo \\
\hline @DielsonFranklin & $\begin{array}{c}\text { Alguém esperava um desfecho diferente? RT @tribunadonorte } \\
\text { 'Protesto dos Pinta' acaba em confusão no Midway http:// } \\
\text { tribuna.me/n87mu }\end{array}$ & Negativo \\
\hline @edborgesolivera & $\begin{array}{c}\text { (RT) Policiamento ao redor do Midway será reforçado } \\
\text { para 'Protesto dos Pinta' http://tribuna.me/tw/n87k1 via @ } \\
\text { tribunadonorte }\end{array}$ & Negativo \\
\hline @fernandobv1 & $\begin{array}{l}\text { (RT) 'Protesto dos Pinta' acaba em confusão no Midway http:// } \\
\text { tribuna.me/tw/n87mu via @tribunadonorte }\end{array}$ & Negativo \\
\hline$@$ Foxx & $\begin{array}{c}\text { \#NatalComoTeAmo RT @tribunadonorte: Policiamento ao } \\
\text { redor do Midway será reforçado para 'Protesto dos Pinta' } \\
\text { http://tribuna.me/n87k1 }\end{array}$ & Positivo \\
\hline @ higorroberto & $\begin{array}{l}\text { "@tribunadonorte: 'Protesto dos Pinta' acaba em confusão no } \\
\text { Midway http://tribuna.me/n87mu " como sempre }\end{array}$ & Negativo \\
\hline$@$ jokcarlos & $\begin{array}{l}\text { "@ canindesoares: “Protesto dos Pinta" acontece dia } 28 \\
\text { no shopping Midway > http://tribuna.me/tw/n875j via @ } \\
\text { tribunadonorte" DIA } 28 \text { BEM LONGE D LA }\end{array}$ & Negativo \\
\hline @Lairinho & $\begin{array}{l}\text { (RT) Policiamento ao redor do Midway será reforçado } \\
\text { para 'Protesto dos Pinta' http://tribuna.me/tw/n87k1 via @ } \\
\text { tribunadonorte }\end{array}$ & Negativo \\
\hline @lima_bielah & $\begin{array}{c}\text { Só em Natal msm“@tribunadonorte: 'Protesto dos Pinta' acaba } \\
\text { em confusão no Midway http://tribuna.me/n87mu " }\end{array}$ & Negativo \\
\hline @Nizardopoeta & $\begin{array}{l}\text { (RT) 'Protesto dos Pinta' acaba em confusão no Midway http:// } \\
\text { tribuna.me/tw/n87mu via @tribunadonorte }\end{array}$ & Negativo \\
\hline
\end{tabular}




\begin{tabular}{|c|c|c|}
\hline Perfil & Interação & Qualificação \\
\hline @patriciaaraujo & $\begin{array}{l}\text { Protesto de imbecis! RT @tribunadonorte Confira fotos do } \\
\text { protesto no Midway Mall http://tribuna.me/a4nl }\end{array}$ & Negativo \\
\hline @ pdrovctor & $\begin{array}{l}\text { (RT) 'Protesto dos Pinta' acaba em confusão no Midway http:// } \\
\text { tribuna.me/tw/n87mu via @tribunadonorte }\end{array}$ & Negativo \\
\hline @renato_natal & $\begin{array}{c}\text { “@tribunadonorte: 'Protesto dos Pinta' acaba em confusão no } \\
\text { Midway http://tribuna.me/n87mu "cacete neles }\end{array}$ & Negativo \\
\hline @RivaJuniorNatal & $\begin{array}{l}\text { (RT) 'Protesto dos Pinta' acaba em confusão no Midway http:// } \\
\text { tribuna.me/tw/n87mu via @ @tribunadonorte }\end{array}$ & Negativo \\
\hline @robertolucena & $\begin{array}{l}\text { (RT) 'Protesto dos Pinta' acaba em confusão no Midway http:// } \\
\text { tribuna.me/tw/n87mu via @tribunadonorte }\end{array}$ & Negativo \\
\hline @ rodrigoekerma & $\begin{array}{c}\text { (Esse é um momento histórico.Poderá gerar+protestos"@ } \\
\text { tribunadonorte: 'Protesto dos Pinta' acaba em confusão no } \\
\text { Midway http://tribuna.me/n87mu " }\end{array}$ & Positivo \\
\hline @simonemartins & $\begin{array}{l}\text { BABADO... 'Protesto dos Pinta' acaba em confusão no } \\
\text { Midway http://tribuna.me/tw/n87mu via @tribunadonorte }\end{array}$ & Negativo \\
\hline @StenioHenrique & $\begin{array}{l}\text { (RT) 'Protesto dos Pinta' acaba em confusão no Midway http:// } \\
\text { tribuna.me/tw/n87mu via @tribunadonorte }\end{array}$ & Negativo \\
\hline
\end{tabular}

Tab. 2. Interações do perfil @tribunadonorte.

Já o perfil @BlogdoBG teve um comportamento diferente, reforçando sua atuação no Twitter, conforme explicitaremos adiante, o que contribui para ampliação de sua relevância na rede social. Por isso, no mesmo período, publicou doze tweets ${ }^{2}$ sobre o tema, sendo oito deles dirigindo os usuários à leitura de posts no Blog, três com informações sem links e um no estabelecimento de uma interação direcionada à outra usuária do Twitter. Nisso já se demonstra uma diferença com relação à atuação dos dois perfis analisados, uma vez que a @tribunadonorte utiliza seu perfil unicamente para difusão das notícias publicadas pelo site, o que explica, inclusive, o fato de que não há interações que tenham origem no perfil do jornal no corpus analisado. Dentre as doze publicações, três foram consideradas favoráveis e oito contrárias ao protesto.

\begin{tabular}{|c|c|c|c|}
\hline Tweet & Data & Valor & $\begin{array}{l}\text { Quantidade de } \\
\text { publicações }\end{array}$ \\
\hline $\begin{array}{l}\text { FOTO: "PINTAS" convocam para manifesto sobre } \\
\text { direito de acesso ao Midway Mall http://migre.me/ } \\
\text { h5EBT }\end{array}$ & $\begin{array}{l}21 \text { de dezembro } \\
\text { de } 2013\end{array}$ & Positivo & 5 \\
\hline $\begin{array}{c}\text { Nesse momento a Av. Bernardo Vieira está } \\
\text { interditada por causa do protesto dos "PINTAS". } \\
\text { O trânsito já começa a congestionar!!! }\end{array}$ & $\begin{array}{l}21 \text { de dezembro } \\
\text { de } 2013\end{array}$ & Negativo & 1 \\
\hline $\begin{array}{l}\text { Protesto dos PINTAS causa tumulto nesse momento } \\
\text { no Midway Mall. Confusão na porta principal. }\end{array}$ & $\begin{array}{l}21 \text { de dezembro } \\
\text { de } 2013\end{array}$ & Negativo & 1 \\
\hline
\end{tabular}

2 Dentre os doze tweets coletados, seis foram repetidos. Para os fins de nossa pesquisa tais publicações serão consideradas apenas uma vez, ainda que indiquemos a quantidade de repetições em tabela a seguir. 


\begin{tabular}{|c|c|c|c|}
\hline Tweet & Data & Valor & $\begin{array}{c}\text { Quantidade de } \\
\text { publicaçốes }\end{array}$ \\
\hline $\begin{array}{l}\text { Várias lojas fechando as portas. Correria nos } \\
\text { corredores do Midway Mall. \#protestoPintas }\end{array}$ & $\begin{array}{l}21 \text { de dezembro } \\
\text { de } 2013\end{array}$ & Negativo & 1 \\
\hline $\begin{array}{c}\text { Informações de @ karolinaoliv3 "Ta tendo arrastao } \\
\text { aqui no Midway Mall, e nao ta podendo sair } \\
\text { ninguem!" }\end{array}$ & $\begin{array}{l}21 \text { de dezembro } \\
\text { de } 2013\end{array}$ & Negativo & 1 \\
\hline $\begin{array}{l}\text { NOVAS FOTOS: protesto dos "PINTAS" provoca } \\
\text { correria e tumulto no Midway : http://ow.ly/rZ8Dz }\end{array}$ & $\begin{array}{l}21 \text { de dezembro } \\
\text { de } 2013\end{array}$ & Negativo & 2 \\
\hline $\begin{array}{c}\text { FOTOS: protesto dos "PINTAS" provoca correria no } \\
\text { Midway : http://ow.ly/rZ8Dz }\end{array}$ & $\begin{array}{c}21 \text { de dezembro } \\
\text { de } 2013\end{array}$ & Negativo & 1 \\
\hline $\begin{array}{l}\text { FOTOS: protesto dos "PINTAS" no Midway causa } \\
\text { apreensão e algumas lojas fecham portas : http:// } \\
\text { ow.ly/rZ8Di }\end{array}$ & $\begin{array}{l}21 \text { de dezembro } \\
\text { de } 2013\end{array}$ & Negativo & 1 \\
\hline $\begin{array}{l}\text { Os sete detidos do 'Protesto dos Pintas' foram } \\
\text { liberados: http://migre.me/h7Bc7 }\end{array}$ & $\begin{array}{l}22 \text { de dezembro } \\
\text { de } 2013\end{array}$ & Negativo & 2 \\
\hline $\begin{array}{l}\text { NOITE DE TERROR: Protesto dos "Pintas" causa } \\
\text { tumulto e pânico no Midway: http://ow.ly/rZaWg }\end{array}$ & $\begin{array}{l}22 \text { de dezembro } \\
\text { de } 2013\end{array}$ & Negativo & 3 \\
\hline $\begin{array}{c}\text { Veja o VÍDEO do protesto dos "pintas" que } \\
\text { aconteceu ontem a noite: http://ow.ly/rZxA5 }\end{array}$ & $\begin{array}{l}23 \text { de dezembro } \\
\text { de } 2013\end{array}$ & Positivo & 4 \\
\hline $\begin{array}{c}\text { Protesto dos "pintas" é convocado para o próximo } \\
\text { sábado: http://migre.me/h8IX8 }\end{array}$ & $\begin{array}{c}23 \text { de dezembro } \\
\text { de } 2013\end{array}$ & Positivo & 2 \\
\hline
\end{tabular}

Tab. 3. Tweets publicados pelo perfil @BlogdoBG

Os doze tweets do perfil @BlogdoBG foram, na verdade, publicados 24 vezes. A partir deles se estabeleceram 19 interações diferentes com outros usuários do Twitter sendo apenas uma delas direcionada a partir do perfil do blog. O @BlogdoBG publicou um número de tweets 140\% superior que a @tribunadonorte acerca do Protesto dos Pintas no período, revelando sua maior ênfase na atuação nas redes sociais.

Das 19 interações do perfil @BlogdoBG, apenas uma foi considerada pelos pesquisadores como manifestante de um discurso favorável ao Protesto. Destaca-se, logo, que enquanto $25 \%$ dos tweets do perfil analisado tenham se posicionado positivamente, apenas 5,3\% de suas interações assim o foram - indicando a configuração de um resultado ainda mais crítico ao protesto do que em relação às interações do perfil @tribunadonorte:

\begin{tabular}{|c|c|c|}
\hline Perfil & Interação & Qualificação \\
\hline \multirow{2}{*}{ @tcmedeiros } & $\begin{array}{c}\text { RT @BlogdoBG: FOTO: "PINTAS" convocam para manifesto } \\
\text { sobre direito de acesso ao Midway Mall http://migre.me/ } \\
\text { h5EBT // Pra fazer baderna?! }\end{array}$ & Negativo \\
& $\begin{array}{c}\text { RT @BlogdoBG NOITE DE TERROR: Protesto dos "Pintas" } \\
\text { causa tumulto e pânico no Midway: http://ow.ly/rZaCi }\end{array}$ & \\
\hline
\end{tabular}




\begin{tabular}{|c|c|c|}
\hline Perfil & Interação & Qualificação \\
\hline @matheusmanieri & $\begin{array}{c}\text { ALÔ PULIÇA RT "@BlogdoBG: FOTO: “PINTAS" convocam } \\
\text { para manifesto sobre direito de acesso ao Midway Mall http:// } \\
\text { migre.me/h5EBT " }\end{array}$ & Negativo \\
\hline @joaoantonioadv & $\begin{array}{l}\text { "@BlogdoBG: FOTO: “PINTAS" convocam para manifesto } \\
\text { sobre direito de acesso ao Midway Mall http://migre.me/ } \\
\text { h5EBT " Era só o que faltava! }\end{array}$ & Negativo \\
\hline @siddjohn & $\begin{array}{c}\text { “@BlogdoBG: Protesto dos "pintas" é convocado para o } \\
\text { próximo sábado: http://migre.me/h8IX8 " querendo, já pode } \\
\text { convocar o BOPE }\end{array}$ & Negativo \\
\hline @MouraNino & $\begin{array}{c}\text { A Polícia vai agir ou vai se esconder?Ação pfv." @ } \\
\text { BlogdoBG:Protesto dos "pintas" é convocado para o próximo } \\
\text { sábado: http://migre.me/h8IX8 " }\end{array}$ & Negativo \\
\hline @_acgadelha & $\begin{array}{c}\text { “@BlogdoBG: Protesto dos "pintas" é convocado para o } \\
\text { próximo sábado: http://migre.me/h8IX8 " esse povo não tem } \\
\text { o q fazer!!! }\end{array}$ & Negativo \\
\hline @aldoclemente & $\begin{array}{c}\text { “@BlogdoBG: Protesto dos "pintas" é convocado para o } \\
\text { próximo sábado: http://migre.me/h8IX8 " quero ver a ação } \\
\text { enérgica da PM! }\end{array}$ & Negativo \\
\hline @VivissAmorim & $\begin{array}{c}\text { Revoluçao dos pinta!!! RT "@BlogdoBG: NOITE DE TERROR: } \\
\text { Protesto dos "Pintas" causa tumulto e pânico no Midway: } \\
\text { http://ow.ly/rZaWg " } \\
\text { Olha @DomMedGuerra RT "@BlogdoBG: Veja o VÍDEO do } \\
\text { protesto dos "pintas" que aconteceu ontem a noite: http:// } \\
\text { ow.ly/rZxA5 " }\end{array}$ & Positivo \\
\hline @FabioJBrito & $\begin{array}{l}\text { “@BlogdoBG: Veja o VÍDEO do protesto dos "pintas" que } \\
\text { aconteceu ontem a noite: http://ow.ly/rZxA5 " só faltava } \\
\text { essa.... }\end{array}$ & Negativo \\
\hline @kaiovilar & $\begin{array}{l}\text { “@ PortalNoArBR } 3 \text { pessoas são detidas e um PM fica ferido } \\
\text { no “Protesto dos Pintas" no Midway http://portalnoar.com/ } \\
\text { tres-pessoas-sao-detidas-e-um-pm-fica-ferido-no-protesto-dos- } \\
\text { pintas-no-midway/ ..." @BlogdoBG diz } 6 \text { detidos }\end{array}$ & Negativo \\
\hline @georgegosson & $\begin{array}{l}\text { “@BlogdoBG: NOITE DE TERROR: Protesto dos "Pintas" causa } \\
\text { tumulto e pânico no Midway: http://ow.ly/rZaWg " Não basta } \\
\text { mais ser NEM NEM. }\end{array}$ & Negativo \\
\hline @ robertobertul & $\begin{array}{c}\text { “@BlogdoBG: NOITE DE TERROR: Protesto dos "Pintas" } \\
\text { causa tumulto e pânico no Midway: http://ow.ly/rZaWg" } \\
\text { Tenso! }\end{array}$ & Negativo \\
\hline @origenesm & $\begin{array}{c}\text { Ahhh uma surra "@BlogdoBG: NOITE DE TERROR: Protesto } \\
\text { dos "Pintas" causa tumulto e pânico no Midway: http://ow.ly/ } \\
\text { rZaWg" }\end{array}$ & Negativo \\
\hline @MsilvaPEP & $\begin{array}{l}\text { Pêia “@BlogdoBG: NOITE DE TERROR: Protesto dos "Pintas" } \\
\text { causa tumulto e pânico no Midway: http://ow.ly/rZaWg" }\end{array}$ & Negativo \\
\hline @CyroRobson & $\begin{array}{l}\text { “@BlogdoBG: NOITE DE TERROR: Protesto dos "Pintas" causa } \\
\text { tumulto e pânico no Midway: http://ow.ly/rZaCi "falta de peia } \\
\text { nesses fuleiros!!! }\end{array}$ & Negativo \\
\hline
\end{tabular}




\begin{tabular}{|c|c|c|}
\hline Perfil & Interação & Qualificação \\
\hline @heribezerra1 & $\begin{array}{c}\text { "E A POLÍCIA ? Rt BlogdoBG NOITE DE TERROR: Protesto dos } \\
\text { "Pintas" causa tumulto e pânico no Midway: http://ow.ly/rZaCi }\end{array}$ & Negativo \\
\hline @P_Capistrano & $\begin{array}{r}\text { "BlogdoBG: Polícia apreende mais de uma tonelada de } \\
\text { maconha em Parnamirim: http://ow.ly/rZ13c "acabaram com o } \\
\text { protesto dos pintas! }\end{array}$ & Negativo \\
\hline @cfredmesquita & $\begin{array}{c}\text { RT "@BlogdoBG: FOTOS: protesto dos "PINTAS" no Midway } \\
\text { causa apreensão e algumas lojas fecham portas : http://ow.ly/ } \\
\text { rZ8Di " }\end{array}$ & Negativo \\
\hline
\end{tabular}

Tab. 4. Interações direcionadas ao perfil @BlogdoBG.

\begin{tabular}{|c|c|c|}
\hline Perfil & Interação & Qualificação \\
\hline @karolinaoliv3 & $\begin{array}{c}\text { Informações de @karolinaoliv3 "Ta tendo arrastao aqui no } \\
\text { Midway Mall, e nao ta podendo sair ninguem!" }\end{array}$ & Negativo \\
\hline
\end{tabular}

Tab.5. Interação direcionada a partir do perfil @BlogdoBG.

Os dados até aqui destacados demonstram a intensidade e o grau de influência e autoridade das manifestações contrárias ao Protesto dos Pintas, uma vez que, além de serem em menor número as manifestações de apoio ao Protesto dos Pintas, a rede de apoiadores aparece desarticulada e, portanto, sem poder de mobilização, contribuindo em muito pouco para a construção de significado do evento junto à opinião pública.

Por outro lado, além de serem em maior número os tweets contra o evento, seus participantes e sua pauta, sua rede é claramente melhor articulada, influenciando decisivamente na construção de significado do protesto - ao menos no Twitter.

A partir disso, já podemos antecipar a observação, como parte da conclusão, de que o Protesto dos Pintas não obteve apoio nem foi visto majoritariamente de uma perspectiva positiva no Twitter - o que implica, necessariamente, no questionamento acerca dos possíveis motivos para que tal situação tenha se estabelecido.

Podemos depreender de Mizruchi (2006, p. 79) que a análise de redes pode explicar a articulação de sujeitos em torno de sua identidade de posicionamentos políticos e ideológicos, como fica evidenciado em nosso caso. Diz Mizruchi (2006, p. 79) que "a teoria das redes pode explicar por que, dado que os amigos de uma pessoa sejam liberais do ponto de vista político, a pessoa em questão também tende a apresentar posições liberais". Assim, a articulação em torno dos dois hubs de nossa rede pode ser compreendida também pelo fato de que os usuários que ali se manifestaram compartilham os pontos de vista políticos e ideológicos expressos pelo perfil @tribunadonorte e pelo perfil @BlogdoBG, o que, por fim, fortalece a construção de uma mesma visão, negativa, sobre o evento do Protesto dos Pintas a partir do Twitter. 


\section{Análise de discurso}

A fim de reconhecer e analisar o discurso que se manifesta na rede e a construção de sentidos operados em torno do Protesto dos Pintas, decidimos selecionar, dentre o corpus coletado, os tweets publicados pelos perfis @tribunadonorte e @BlogdoBG a respeito do tema e os tweets que marcaram suas interações, destacados nas tabelas 2, 4 e 5 . Para isso recorreremos às noções de Foucault (2008) e Charaudeau (2006).

Foucault (2008) entende que o discurso é o lugar onde se exerce o poder. Discurso e linguagem confundem-se com situações específicas em que se manifestam relações sociais que apontam relações de poder.

Mas, para Foucault, o discurso é mais que isso, sendo entendido como categórico, decisivo, pertencendo à ordem das leis. E se é poderoso, diz, seu poder "é de nós, só de nós, que lhe advém" (FOUCAULT, 2008, p.7). O discurso é produzido de tal maneira que possa manter-se controlado, organizado, selecionado, entre outros elementos que servem para avaliar riscos, acumular poder, dominar o acontecimento e desviar a atenção de sua materialidade (FOUCAULT, 2008, p.9). É preocupação de Foucault (2008) detectar os mecanismos da linguagem que, ao mesmo tempo em que garantem a manutenção do poder, excluem do discurso sujeitos diferentes por diferentes motivos.

Uma das maneiras mais evidentes de exclusão é a chamada interdição de linguagem: só fala quem tem poder, e a fala realiza esse poder, instituindo-o no sujeito que pronuncia o discurso. Outra ferramenta de exclusão é a separação e a rejeição ${ }^{3}$. O discurso é então o lugar em que se exerce o poder de separação dos elementos e sujeitos que devem ser excluídos da sociedade: quem pronuncia o discurso, o faz, separando. A terceira forma que o discurso exclui, segundo Foucault (2008), é através daquilo que ele chama de vontade da verdade: o discurso define o verdadeiro em oposição ao falso, sendo o verdadeiro instituído no poder do discurso. O que foge ao poder e ao discurso é excluído em prol da manutenção do poder. Quem se põe em choque com a dimensão discursiva vai ser excluído e segregado como um herege, uma vez que fala ou formula enunciados inassimiláveis aos padrões do discurso enquanto vontade da verdade. O herege, que desafia o discurso oficial, deverá ter sua fala interditada e será excluído do seu grupo social.

Os elementos expostos por Foucault (2008), que descrevemos acima, têm relevância para nossa análise dos tweets e posts publicados pelos perfis @tribunadonorte e @ BlogdoBG e que contribuíram na construção dos sentidos acerca do Protesto dos Pintas, uma vez que podemos perceber em diversas dessas manifestações de exclusão por meio do discurso expresso - interdição do direito de se expressar em um protesto e exclusão dos "pintas", caracterizando a rejeição a seu protesto, além das afirmações peremptórias de uma pretensa "verdade" acerca dos sujeitos e dos eventos.

3 Um exemplo de como se constituem discursivamente a separação e a rejeição percebe-se na história da loucura. A palavra dos loucos sempre teve de ser excluída. 
Em primeiro lugar, destaquemos as publicações que manifestam o poder de fala dos que atribuem o sentido do \#ProtestodosPintas em detrimento de seus próprios participantes e realizadores. Desse modo, percebe-se que nos hubs analisados é de poucos o poder de fala - em geral da polícia ou críticos do movimento.

O poder, nesses textos, pertence a forças policiais e ao discurso que se coloca em oposição ao \#ProtestodosPintas. Isso também se evidencia ao destacarmos que protestar é, por sua vez, a expressão de uma fala. Quem protesta ou o faz porque pode falar ou para que tenha o poder de falar. Assim, a repressão do protesto assim como falas que defendam tal repressão manifestam iniciativas de tentativa de interdição da expressão dos "pintas" - para tais sujeitos que se colocaram contra o \#ProtestodosPintas, os Pintas não têm nem podem ter o poder da fala.

É o que afirma, por exemplo, o perfil @anasiqr: “Protesto virou moda, até 'os pinta'. Já pensou". Já o perfil @patriciaaraujo desqualifica o direito de protesto ao denominá-lo de "Protesto de imbecis!". O perfil @joaoantonioadv e o perfil @FabioJBrito expressaram-se de maneira semelhante, afirmando que o Protesto "era o que faltava", frase que denota um sentido de desaprovação e surpresa, semelhante ao "Só em Natal”, de @lima_bielah. Por sua vez, o perfil @_acgadelha expressou-se afirmando que "esse povo não tem o q fazer!!!»»

Alguns perfis que se manifestaram no Twitter defenderam ainda mais explicitamente a repressão contra o direito de fala dos Pintas expresso no protesto:

@renato_natal: “@tribunadonorte: 'Protesto dos Pinta' acaba em confusão no Midway http://tribuna.me/n87mu "cacete neles

@siddjohn: “@BlogdoBG: Protesto dos "pintas" é convocado para o próximo sábado: http://migre.me/h8IX8 " querendo, já pode convocar o BOPE @MouraNino: A Polícia vai agir ou vai se esconder?Ação pfv.» @BlogdoBG:Protesto dos "pintas" é convocado para o próximo sábado: http://migre.me/h8IX8 " @matheusmanieri: ALÔ PULIÇA RT «@BlogdoBG: FOTO: “PINTAS" convocam para manifesto sobre direito de acesso ao Midway Mall http://migre.me/h5EBT " @aldoclemente: “@BlogdoBG: Protesto dos "pintas" é convocado para o próximo sábado: http://migre.me/h8IX8 " quero ver a ação enérgica da PM!

@CyroRobson: “@BlogdoBG: NOITE DE TERROR: Protesto dos "Pintas” causa tumulto e pânico no Midway: http://ow.ly/rZaCi "falta de peia nesses fuleiros!!! @origenesm: Ahhh uma surra “@BlogdoBG: NOITE DE TERROR: Protesto dos "Pintas" causa tumulto e pânico no Midway: http://ow.ly/rZaWg " @MsilvaPEP: Pêia "@BlogdoBG: NOITE DE TERROR: Protesto dos "Pintas" causa tumulto e pânico no Midway: http://ow.ly/rZaWg" @ heribezerra1: "E A POLíCIA ? Rt BlogdoBG NOITE DE TERROR: Protesto dos «Pintas» causa tumulto e pânico no Midway: http://ow.ly/rZaCi

Destaca-se que, à exceção da interação do perfil @renato_natal com o perfil @tribunadonorte, um dos hubs da rede analisada, as demais manifestações com pedidos 
de intervenção da polícia (violenta ou não) se deram na interação com o outro hub da rede, o perfil @BlogdoBG. Recuperando o que dissemos anteriormente, a partir de Mizruchi (2006), a identidade de posicionamentos políticos e ideológicos nas redes sociais pode explicar tal situação, aduzindo que as manifestações do perfil @BlogdoBG se aproximam das construções discursivas que mais criminalizam e promovem violentamente a repressão ao poder de fala dos manifestantes - em nenhum dos textos apontados em suas publicações no Twitter há falas de organizadores ou participantes do \#ProtestodosPintas. Isso ainda se torna mais evidente pelo uso das expressões "NOITE DE TERROR" (em caixa alta), "tumulto" e "pânico", reforçando a intenção de desqualificar o protesto e construindo um sentido amplamente negativo ao pleito, em torno do quê se organizam na rede os perfis com discursos mais repressivos, conforme destacados acima.

Protestos sempre são considerados uma afronta por uma parcela da sociedade que se filia a um discurso que os vê como confusão ou baderna. No entanto, nesse caso, as manifestações vão ainda mais longe nessa questão por, na verdade, exporem a tese de que aos "pintas", parcela marginalizada no imaginário social de determinado campo social, não deve ser concedido o direito de expressão nem o poder de fala na forma de um protesto. Há, aparentemente, um elemento de preconceito de classe e raça desvelado nessa expressão - uma forma de estranhamento e nojo (MILLER, 1997).

Estas ponderações nos conduzem a uma proposta analítica com base em Charaudeau (2006, p.41) que compreende que a construção de sentido se dá através de dois processos que ele chama de transformação e de transação. O processo de transformação sinaliza a passagem do "mundo a significar" em "mundo significado". Esse processo aponta para operações de linguagem que fazem com que acontecimentos cotidianos possam ser transformados em informações. É a transformação do elemento da realidade social em notícia. Esse processo é analisado por Charaudeau (2006, p.41) em cinco etapas.

A primeira delas é a identificação dos seres do mundo, nomeando-os. Nomear é um ato de poder e controle sobre o objeto nomeado. A palavra e a nomeação se fundamentam em uma relação arbitrária que, no campo do discurso, é essencial para a organização dos sentidos - é preciso identificar as coisas do mundo, vinculando-lhes as representações das palavras.

No caso do discurso da informação, a nomeação é parte do processo de identificação do mundo a significar no mundo significado. Ela se traduz pela descrição dos fatos a serem transformados em notícia, ou seja, sua identificação - de objetos, fatos e personagens.

Desse modo, não é à toa que o \#ProtestodosPintas é nomeado como "noite de terror”, “tumulto", “pânico”", “confusão”, "protesto de imbecis”, entre outras expressões. É preciso dar nome e só pode dar nome ao protesto quem tem o poder de falar. Ao nomear, os usuários da rede, assim como seus hubs, sustentam o devido lugar que cabe aos "pintas" e à sua manifestação. Tendo o poder de significar os eventos, qualifica-os de acordo com seus interesses interditando o direito de protesto e construindo um sentido 
negativo a seu respeito. Tal processo de transformação discursiva, segundo Charaudeau (2006, p.41), é a qualificação das coisas nomeadas. Não basta nomear os objetos, citar os fatos e personagens. No fluxo de construção das informações e notícias esses elementos necessitam ser qualificados - provavelmente, a instância da construção e da operação discursiva em que as intenções e ideologias dos sujeitos que arregimentam o discurso são melhor expressas. A qualificação não é uma simples adjetivação dos sujeitos e das coisas - ela implica uma opinião, carregada de ideologia e intenção, constituindo-se em um dos elementos de enquadramento das informações e das notícias.

Em seguida, entram os elementos discursivos de narração propriamente dita. Trata-se de uma descrição das ações, nas quais se engajam os sujeitos e as coisas que foram consideradas no discurso, que Charaudeau (2006, p.41) resume como sendo o fornecimento das razões e motivos das ações descritas. A narrativa acerca do \#ProtestodosPintas, por exemplo, traduz uma "noite de terror": "Protesto dos 'Pintas' causa tumulto e pânico no Midway". Se é um "protesto de imbecis", um "tumulto", a narrativa do evento deve prescindir de relatos sobre possíveis violências policiais e centrar suas observações sobre “arrastões”, “lojas fechadas”, “pânico”. No perfil @BlogdoBG não encontramos quaisquer referências, por exemplo, a relatos de violência policial - a não ser em interações que, na verdade, solicitavam a ação violenta da polícia (“cacete neles”, "querendo, já pode convocar o BOPE", por exemplo $)^{4}$.

Tais sentidos negativos acerca do protesto foram sedimentados a partir do processo de transação, conforme descrito por Charaudeau (2006). A construção de sentidos acerca dos eventos em torno do \#ProtestodosPintas, a nossa análise demonstra, resulta, além das publicações no twitter, da interação entre sujeitos agentes na rede, seus emissores e receptores que intercambiam posições diante de um discurso. O sentido, desse modo, é resultado de um discurso que se realiza em uma relação social, o que é evidente em nosso caso. É na relação que os sentidos se constroem.

A percepção contrária ao \#ProtestodosPintas manifesta na rede que analisamos é, portanto, resultado de um complexo jogo em que se relacionam os posicionamentos ideológicos dos usuários que interagem e dos hubs da rede, enunciados constituídos a partir de uma perspectiva que visa interditar os discursos e as manifestações dos "pintas" e, consolidando tudo isso, a própria constituição da rede e de suas interações que, por fim, estabelece e sedimenta uma visão amplamente contrária ao \#ProtestodosPintas e, mais que isso, ao poder de fala e ao direito de manifestação de tais sujeitos.

\section{Considerações finais}

Nossa análise destacou como o funcionamento da rede analisada, as manifestações dos sujeitos e as suas interações serviram, prioritariamente, para a construção de

4 Outras noções apresentadas por Charaudeau (2006), como a modalização, não serão abordadas aqui uma vez que não se aplicam à análise de nosso corpus. 
uma perspectiva negativa do evento do \#ProtestodosPintas, representando os sentidos discursivos das representações a respeito desse grupo nas mídias tradicionais - a rede funcionou, em outras palavras, para reforçar o estranhamento, o nojo, o preconceito e a visão negativa acerca dos Pintas e seu protesto.

O trabalho também evidenciou como interagiram e influenciaram, como hubs, os perfis @tribunadonorte e @BlogdoBG, ainda que este último tenha uma inserção muito mais intensa no twitter enquanto o primeiro atua a fim de conduzir leitores para o seu site.

Foucault muito nos disse sobre a forma de historicizar o mundo de forma crítica e contínua. Somos nós que construímos os discursos e as narrativas. As próprias descrições dos pesquisadores são puras interpretações de documentos. Os resultados de pesquisa são construídos a partir, não apenas dos fatos da realidade objetiva, mas sim, e principalmente, da interpretação social dos fatos.

\author{
Maria das Graças Pinto Coelho é professora da UFRN. \\ gpcoelho8@gmail.com \\ Daniel Dantas Lemos é professor da UFRN. \\ danieldantas79@uol.com.br
}

\title{
Referências
}

CHARAUDEAU, P. Discurso das mídias. Tradução por Angela S. M. Corrêa. São Paulo: Contexto, 2006 FAUSTO NETO, A. "Fragmentos de uma analítica da midiatização". In: Matrizes, v.1, n.2, p. 89-105, abr. 2008.

FOUCAULT, M. A ordem do discurso. Tradução por Laura Fraga de Almeida Sampaio.17aEd. São Paulo: Loyola, 2008.

GEPHI. Graph Visualization and Manipulation: software livre. Versão Gephi 0.8.2 201210100934. França: Gephi.org, 2014. Disponível em: <www.https://gephi.org/>. Acesso em: 31 jan. 2014.

MELO, I. D. ; SILVA, L. A. L. F.; SARMENTO, R. A. V.; FERNANDES, V. S. Análise de Redes Sociais. Disponível em: http://www.nigam.info/docs/pesquisa/artigo1.pdf, acessado em 03 fev 2014.

MILLER, W. I. The anatomy of disgust. Cambridge: Harvard University Press, 1997.

MIZRUCHI, M. S."Análise de redes sociais: avanços recentes e controvérsias atuais». Revista de Administração de Empresas, v.46, n. 3, jul/set, 2006.

RECUERO, R. Redes sociais na Internet: Considerações iniciais. E Compós, v. 2, 2005. 